\title{
Aggression in autism spectrum disorder: presentation and treatment options
}

\author{
This article was published in the following Dove Press journal: \\ Neuropsychiatric Disease and Treatment \\ 23 June 2016 \\ Number of times this article has been viewed
}

\section{Sarah E Fitzpatrick \\ Laura Srivorakiat \\ Logan K Wink \\ Ernest V Pedapati \\ Craig A Erickson}

Cincinnati Children's Hospital Medical

Center, University of Cincinnati

College of Medicine, Cincinnati, $\mathrm{OH}$, USA
Correspondence: Craig A Erickson Cincinnati Children's Hospital Medical Center, University of Cincinnati College of Medicine, 3333 Burnet Avenue, Cincinnati, OH 45229-3026, USA

Tel +I 5136366265

Fax +I 5136363800

Email craig.erickson@cchmc.org

\begin{abstract}
Autism spectrum disorder (ASD) is a neurodevelopmental disorder characterized by persistent difficulties in social communication and social interaction, coupled with restricted, repetitive patterns of behavior or interest. Research indicates that aggression rates may be higher in individuals with ASD compared to those with other developmental disabilities. Aggression is associated with negative outcomes for children with ASD and their caregivers, including decreased quality of life, increased stress levels, and reduced availability of educational and social support. Therapeutic strategies including functional behavioral assessment, reinforcement strategies, and functional communication training may have a significant impact in reducing the frequency and intensity of aggressive behavior in individuals with ASD. Pharmacologic treatments, particularly the use of second-generation antipsychotics, may also be of some benefit in reducing aggression in individuals with ASD. With the ever-increasing rate of ASD diagnosis, development of effective therapeutic and pharmacologic methods for preventing and treating aggression are essential to improving outcomes in this disorder.
\end{abstract}

Keywords: autism, autism spectrum disorder, aggression, treatment, antipsychotics, applied behavior analysis

\section{Introduction}

Autism spectrum disorder (ASD) is a neurodevelopmental disorder characterized by persistent difficulties in social communication and social interaction, coupled with restricted, repetitive patterns of behavior or interest. ${ }^{1}$ Children with ASD may present with additional maladaptive behaviors, including aggression, self-injury, and severe tantrums (also referred to in this text as irritability), which researchers suggest can cause families greater stress than the core features of ASD. ${ }^{2,3}$

\section{Defining aggression}

Aggression is generally characterized as behavior that is threatening or likely to cause harm and may be verbal (eg, threatening or cursing at another person) or physical (eg, hitting, biting, or throwing objects at another person). A person can demonstrate one form of aggressive behavior or many, with variable frequency, intensity, and duration. Because of the variable nature of aggressive behavior, researchers have defined aggression in many different ways. For example, the Aberrant Behavior Checklist Irritability subscale (ABC-I), ${ }^{4}$ the responses on a computer task showing aggressive stimuli, ${ }^{5}$ the aggression subscale of the Child Behavior Checklist, ${ }^{6,7}$ and the behavior recordings noted during experimental analysis of behavior ${ }^{8}$ all capture slightly different aspects of aggression. This variability creates challenges in comparing aggression between individuals and across research studies. In response, researchers 
are increasingly utilizing multiple measures and methods of defining aggression, which may ultimately allow for clearer interpretation of data and improve ease of comparison.

\section{Prevalence}

Research indicates that rates of aggressive behavior may be higher in individuals with ASD compared to typically developing peers and those with other developmental disabilities, though this is inconsistently reported in the literature. In some studies, individuals diagnosed with intellectual disability (ID) and comorbid ASD are reported to more frequently demonstrate aggression than individuals with ID alone. ${ }^{9,10}$ In contrast, one study reports that a group of younger children with ASD showed less aggression compared to a control group of age-matched children, although older children with ASD in this study demonstrated higher aggression rates. ${ }^{6}$ Furthermore, ASD-specific research has yielded variable aggression prevalence rates. Kanne and Mazurek ${ }^{11}$ demonstrated that $56 \%$ of individuals with ASD $(n=1,380)$ directed aggression toward caregivers and $32 \%$ directed aggression toward noncaregivers. In addition, $68 \%$ of these individuals had a history of directing aggression toward caregivers, and $49 \%$ had a history of directing aggression toward noncaregivers. ${ }^{11}$ Other studies found a lower prevalence of aggression in ASD. In a population of adults with ID and comorbid ASD, 15\%-18\% were found to engage in aggression toward others. ${ }^{12}$ Scores in the clinically significant range for aggression on a broad behavioral measure were found in $22 \%$ of young children diagnosed with autistic disorder in another study. ${ }^{7}$ In a population of children with an educational diagnosis of pervasive developmental disorder, between $9 \%$ and $14 \%$ were reported to exhibit aggression. ${ }^{3}$

\section{Aggression risk factors}

Certain factors, such as young age, tend to predict aggression levels for children in the general population. ${ }^{13,14}$ In ASD, however, risk factors may be unique from those identified in typically developing or developmentally disabled children. For example, in typically developing children, boys tend to exhibit aggression more frequently than girls $;{ }^{13}$ however, sex has not been found to predict the frequency of aggression in ASD.${ }^{67}$ Likewise, social factors (ie, level of parent education and marital status) that predict aggression in typically developing children have not been consistently predictive of aggression in children with ASD. ${ }^{11}$ Specific features of ASD may drive aggressive behavior. Reese et $\mathrm{al}^{15}$ found that children with ASD frequently engaged in aggression to gain access to ritualistic or repetitive behaviors. Language ability, intellectual quotient, and adaptive functioning also have been implicated as predictors of aggressive behavior in children with ASD. ${ }^{7,16}$

\section{Negative outcomes related to aggression}

Aggression is clearly associated with negative outcomes for children with ASD, including impaired social relationships, ${ }^{17}$ placement in restrictive school or residential settings, ${ }^{18}$ use of physical intervention, ${ }^{19}$ and increased risk of being victimized. ${ }^{20}$ Aggressive behaviors can also contribute to school provider burnout, ${ }^{21}$ leading to probable impact on the quality of education. Aggression also contributes to negative outcomes for caregivers of youth with ASD, including increased stress levels, ${ }^{22}$ financial problems, lack of support services, and negative impact on day-to-day family life and well-being. ${ }^{23}$ Clearly addressing aggressive behavior is pivotal to improving outcomes for individuals with ASD and their caregivers.

\section{Nonpharmacological treatment of aggression}

Learning theory and operant behavior principles form the basis for current behavioral treatments of aggression in ASD. ${ }^{24}$ These principles rely on careful observation and definition of behavior, as well as the recognition that behavior serves a purpose (or function). ${ }^{25}$ There has been tremendous evolution of behavioral technology encompassing a number of strategies (eg, functional behavior assessment [FBA] and schedules of reinforcement) that can be used in an applied manner to increase useful behavior and reduce harmful behaviors. Considered together, these strategies are known as applied behavioral analysis. ${ }^{26}$ The applied behavior analytic strategies described later have met criteria as evidence-based practices for the treatment of challenging behavior in autism in numerous studies, with their effectiveness being reaffirmed in recent research detailed next. ${ }^{27,28}$

\section{Functional behavior assessment}

The function (or purpose) of a behavior is the desirable consequence the behavior creates, which causes the behavior to persist. FBA is the process of gathering data to determine what desirable consequences maintain a person's behavior. Social attention, access to preferred items/activities, removal of demands or other unpleasant stimuli, and access to sensory stimulation have been identified as desirable consequences likely to maintain a behavior. ${ }^{29}$ Powers et $\mathrm{al}^{24}$ argued that FBA should form the foundation of any behavioral treatment. When FBA is not conducted, clinicians run the risk of applying inappropriate treatment and potentially worsening behavior. For example, the application of a time-out 
from attention may also promote escape from demands and increased aggressive behavior if the function of the aggression is escape, not attention.

Multiple methods exist for conducting FBA. Caregiver questionnaires, such as the Questions About Behavioral Function questionnaire ${ }^{30}$ or the Functional Assessment Screening Tool, ${ }^{31}$ can be helpful in screening for behavioral function. Direct observation and recording of a target behavior, as well as the events that precede and follow the target behavior, may aid hypotheses generation about behavioral function. ${ }^{26}$ The most rigorous method of FBA is direct experimental functional analysis, setting up situations in which antecedents and consequences are systematically manipulated to determine their effect on behavior. ${ }^{24}$ Newcomer and Lewis ${ }^{32}$ found that interventions informed by an FBA are more effective than those that are not. Interventions informed by an experimental functional analysis have been shown to be more efficacious than other FBA methods. ${ }^{33}$ Research in this area is currently focused on altering functional analysis procedures to increase accessibility and social validity of functional analysis procedures across environments. Some of these alterations include utilization of brief functional analysis, ${ }^{34}$ screening for specific functions, ${ }^{35}$ and directly involving caregivers in assessment procedures. ${ }^{36}$

\section{Reinforcement strategies}

Reinforcement involves providing desirable consequences following a behavior to increase the likelihood that the behavior will occur again. ${ }^{37}$ There are several types of reinforcement strategies. Differential reinforcement strategies are based on the occurrence of the target problem behavior or adaptive behaviors, which include providing reinforcement in the absence of problem behavior (ie, differential reinforcement of other behavior), when the person engages in a behavior incompatible with the form of aggressive behavior (ie, differential reinforcement of other behavior), or when an appropriate behavior serving the same functional purpose as the aggression is demonstrated (ie, differential reinforcement of alternative behavior). Within the last 20 years, differential reinforcement of other behavior has been one of the most frequently used treatments for aggression in ASD. ${ }^{38}$ Wong et $\mathrm{al}^{27}$ determined that differential reinforcement strategies should be considered as an evidence-based practice when working with children, youth, and young adults with ASD; Roth et $\mathrm{al}^{28}$ found that differential reinforcement strategies showed a medium effect size in the treatment of problem behavior in adolescents and adults with ASD. Noncontingent reinforcement (NCR) strategies, which are not dependent on the occurrence of behavior, also demonstrated effectiveness in decreasing aggression ${ }^{39}$ and problem behaviors maintained by various functions. ${ }^{24} \mathrm{~A}$ review of NCR research indicated that NCR on a fixed-time schedule with extinction and thinning of the schedule should be considered as a wellestablished, evidence-based treatment. ${ }^{40}$

\section{Functional communication training}

Functional communication training (FCT) involves teaching a person to appropriately request access to a desirable consequence (eg, social attention, preferred items/activities, or escape from a nonpreferred activity) to reduce inappropriate behaviors. For example, teaching a child to touch a picture of his mother to ask for her attention, rather than hitting her to obtain attention. Carr and Durand ${ }^{41}$ supported FCT as an appropriate treatment for individuals presenting with aggressive behavior. A review of research on the treatment of aggression conducted 2 decades later found FCT to be one of the most commonly used behavioral treatments for aggression. ${ }^{38}$ Braithwaite and Richdale ${ }^{42}$ found that FCT was effective in decreasing aggression that historically resulted in escape or access to tangibles. FCT was also effective in decreasing both targeted aggressive and destructive behaviors and nontargeted disruptive behavior. ${ }^{43}$ When used in conjunction with extinction, FCT meets criteria for a wellestablished treatment as set forth by Divisions 12 and 16 of the American Psychological Association in their criteria for empirically supported treatments. ${ }^{44}$

\section{Pharmacological treatments of aggression}

The combined negative impact and frequent occurrence of aggressive behavior in individuals with ASD have been factors in driving the focus of pharmacologic research on ASD-associated irritability (including aggression, tantrums, and self-injury) over the last 50 years. Second-generation antipsychotics (SGAs) are the most commonly employed first-line pharmacotherapy options for the treatment of aggression in ASD. Following several large randomized, placebo-controlled trials that demonstrated robust reduction in aggressive behavior with treatment in youth with ASD, risperidone and aripiprazole were approved by the US Food and Drug Administration (FDA) for the treatment of irritability in this population. ${ }^{45-47}$ First-generation antipsychotics, antiepileptic medications (AEDs), mood stabilizers, and several glutamatergic modulators are also frequently employed for the treatment of ASD-associated irritability, though with less robust evidence supporting their use (Table 1 for a brief review of selected controlled pharmacologic trials in ASD). 
Table I Pharmacologic management of aggression in ASD, selected controlled trials

\begin{tabular}{|c|c|c|c|c|c|c|}
\hline Medication & Author & Study design & $\mathbf{N}$ & Age (years) & Details & AEs \\
\hline \multicolumn{7}{|c|}{ Antipsychotics/selected controlled trials } \\
\hline \multirow[t]{2}{*}{ Haloperidol } & Campbell et a ${ }^{92}$ & I2-week, RPCT & 42 & $2.6-7.8$ & $\begin{array}{l}\text { Haloperidol superior } \\
\text { to placebo on } \\
\text { stereotypy and social } \\
\text { withdraw subscales } \\
\text { of CPRS }\end{array}$ & $\begin{array}{l}\text { Sedation, acute dystonic } \\
\text { reaction in two subjects }\end{array}$ \\
\hline & Anderson et a $\left.\right|^{94}$ & I4-week, RPCT & 45 & $2.3-7.9$ & $\begin{array}{l}\text { Haloperidol superior } \\
\text { to placebo on all } \\
\text { subscales of CPRS }\end{array}$ & $\begin{array}{l}\text { Sedation, increased } \\
\text { irritability }\end{array}$ \\
\hline \multirow[t]{6}{*}{ Risperidone } & McDougle et $\mathrm{al}^{50}$ & I2-week, RPCT & 31 & $18-43$ & $\begin{array}{l}\text { Risperidone superior } \\
\text { to placebo on CGI-I } \\
\text { and SIB-Q }\end{array}$ & $\begin{array}{l}\text { Abnormal gait }(n=l) \text {, } \\
\text { sedation }\end{array}$ \\
\hline & McCracken et al ${ }^{46}$ & 8-week, RPCT & 101 & $5-17$ & $\begin{array}{l}\text { Risperidone superior } \\
\text { to placebo on } A B C-I \\
\text { and } C G I-I\end{array}$ & $\begin{array}{l}\text { Weight gain, increased } \\
\text { appetite, fatigue }\end{array}$ \\
\hline & Shea et $\mathrm{al}^{51}$ & 8-week, RPCT & 79 & $5-12$ & $\begin{array}{l}\text { Risperidone superior } \\
\text { to placebo on } A B C-I\end{array}$ & Somnolence, weight gain \\
\hline & RUPP52 & $\begin{array}{l}\text { Part I: I6-week } \\
\text { open-label } \\
\text { extension of } \\
2002 \text { trial }\end{array}$ & Part I: 63 & $5-17$ & $\begin{array}{l}\text { Sustained } \\
\text { improvement on } \\
A B C-I\end{array}$ & Weight gain \\
\hline & & $\begin{array}{l}\text { Part 2: 8-week } \\
\text { DB placebo- } \\
\text { substitution study }\end{array}$ & Part 2: 32 & $5-17$ & $\begin{array}{l}62.5 \% \text { relapse rate in } \\
\text { placebo group }\end{array}$ & $\begin{array}{l}\text { Increased aggression in } \\
\text { placebo group }\end{array}$ \\
\hline & Aman et $\mathrm{al}^{53}$ & $\begin{array}{l}\text { Naturalistic } \\
2 \text { I-month } \\
\text { follow-up }\end{array}$ & 84 & $5-17$ & $\begin{array}{l}\text { Improved scores on } \\
A B C-I ; \text { significant } \\
\text { rate of continued use }\end{array}$ & $\begin{array}{l}\text { Weight gain, excessive } \\
\text { appetite, enuresis }\end{array}$ \\
\hline \multirow[t]{3}{*}{ Aripiprazole } & Marcus et $\mathrm{al}^{58}$ & $\begin{array}{l}\text { 8-week, RPCT } \\
\text { (fixed dose) }\end{array}$ & 218 & $6-17$ & $\begin{array}{l}\text { Aripiprazole superior } \\
\text { to placebo on } A B C-I\end{array}$ & $\begin{array}{l}\text { Weight gain, sedation, } \\
\text { EPS }\end{array}$ \\
\hline & Owen et $\mathrm{al}^{47}$ & $\begin{array}{l}\text { 8-week, RPCT } \\
\text { (flexible dose) }\end{array}$ & 98 & $6-17$ & $\begin{array}{l}\text { Aripiprazole superior } \\
\text { to placebo on } A B C-I \\
\text { and } C G I-I\end{array}$ & Weight gain \\
\hline & Marcus et $\mathrm{al}^{59}$ & $\begin{array}{l}\text { 52-week open- } \\
\text { label extension of } \\
2009 \text { trial }\end{array}$ & 330 & $6-17$ & $\begin{array}{l}\text { Aripiprazole superior } \\
\text { to placebo on } A B C-I \\
\text { and } C G I-I\end{array}$ & $\begin{array}{l}\text { Weight gain, increased } \\
\text { appetite, vomiting, } \\
\text { insomnia }\end{array}$ \\
\hline Olanzapine & Hollander et $\mathrm{al}^{73}$ & 8-week RPCT & II & $6-14$ & $\begin{array}{l}\text { Olazapine superior } \\
\text { to placebo on CGI-I, } \\
\text { but not on CY- } \\
\text { BOCS or OAS-M }\end{array}$ & Weight gain, sedation \\
\hline Lurasidone & Loebel et al ${ }^{90}$ & $\begin{array}{l}\text { 6-week RPCT } \\
\text { (fixed dose) }\end{array}$ & 150 & $6-17$ & $\begin{array}{l}\text { Lurasidone not } \\
\text { superior to placebo } \\
\text { at either dose }\end{array}$ & Vomiting, somnolence \\
\hline \multicolumn{7}{|c|}{ Antiepileptic medications/selected controlled trials } \\
\hline Valproic acid & Hellings et al ${ }^{99}$ & 8-week RPCT & 30 & $6-20$ & $\begin{array}{l}\text { Valproic acid not } \\
\text { superior to placebo } \\
\text { on } A B C-I\end{array}$ & $\begin{array}{l}\text { Skin rash, weight gain, } \\
\text { elevated ammonia }\end{array}$ \\
\hline \multicolumn{7}{|c|}{ Other medications/selected controlled trials } \\
\hline $\mathrm{N}$-acetylcysteine (NAC) & Hardan et al ${ }^{109}$ & I2-week RPCT & 29 & $3.2-10.7$ & $\begin{array}{l}\text { NAC superior to } \\
\text { placebo on } A B C-I\end{array}$ & $\begin{array}{l}\text { Minimal gastrointestinal } \\
\text { symptoms }\end{array}$ \\
\hline Naltrexone & Campbell et al ${ }^{1 / 4}$ & 6-week RPCT & 41 & 2.9-7.8 & $\begin{array}{l}\text { Improved } \\
\text { hyperactivity on } \\
\text { CPRS but no } \\
\text { improvement in self- } \\
\text { injury }\end{array}$ & Well tolerated \\
\hline
\end{tabular}

Abbreviations: AEs, adverse events; ASD, Autism spectrum disorder; RPCT, randomized placebo-controlled trial; CPRS, Children's Psychiatric Rating Scale; CGIII, Clinical Global Impressions-Improvement scale; SIB-Q, Self-Injurious Behavior Questionnaire; ABC-I, Aberrant Behavior Checklist Irritability subscale; RUPP, Research Units on Pediatric Psychopharmacology; DB, double-blind; EPS, extrapyramidal symptoms; CY-BOCS, Children's Yale-Brown Obsessive Compulsive Scale; OAS-M, Overt Aggression Scale modified. 


\section{Second-generation antipsychotics Risperidone}

Risperidone is a robust $\mathrm{D}_{2}$ receptor antagonist initially developed as a treatment for schizophrenia. Numerous case reports, open-label studies, and double-blind, placebo-controlled trials have demonstrated its efficacy as a treatment for ASDassociated aggression, self-injury, and severe tantrums, and risperidone became the first medication approved by the FDA to treat irritability in youth with ASD. ${ }^{48}$ The first study of risperidone in subjects diagnosed with ASD - an open-label study using $0.5-1.5 \mathrm{mg} / \mathrm{d}$ of risperidone in eleven autistic males aged 6-34 years old - found a significant decrease in aggression, self-injurious behavior (SIB), and explosivity after 4 months of treatment. ${ }^{49}$

In 1998, McDougle et al ${ }^{50}$ conducted the first doubleblind, randomized, placebo-controlled trial of risperidone in ASD. Thirty-one adults aged 18-43 years (15 risperidone, 16 placebo) enrolled in the study, with 24 individuals completing 12 weeks of treatment. Seven subjects withdrew prior to study completion because of adverse effects (including extrapyramidal symptoms [EPS] and agitation). The subjects in the risperidone group who completed the trial showed a significant global improvement measured by the Clinical Global Impression-Improvement scale (CGI-I) and a decrease in physical aggression, self-injury, and property destruction as measured by the SIB Questionnaire (SIB-Q).

In 2002, the Research Units on Pediatric Psychopharmacology (RUPP) Autism Network published the results of an 8-week, randomized, double-blind, placebo-controlled trial of risperidone in 101 youth (5-17 years) with ASD and comorbid aggression. ${ }^{46}$ In this trial, subjects treated with risperidone had a significant decrease in the mean ABC-I score $(P<0.001)$. Sixty-nine percent of participants in the risperidone group were deemed treatment responders (defined as 25\% improvement on the ABC-I and a rating of "much improved" or "very much improved" on the CGI-I) compared to $12 \%$ of subjects on placebo $(P<0.001)$. Subsequently, a 2004 8-week, randomized, double-blind, placebocontrolled trial in 79 children aged 5-12 years old with ASD confirmed the effectiveness of risperidone for treating irritability and aggression in ASD. ${ }^{51}$ This study found a significant improvement on the ABC-I, global improvement on the other four $\mathrm{ABC}$ subscales, and significant improvement on the Visual Analog Scale parent-defined target behavior in the risperidone group compared to placebo.

In 2005, as a follow-up to their 2002 study, the RUPP group examined the longer-term benefits of risperidone. ${ }^{52}$ Subjects who showed a positive response to risperidone and subjects who were placebo nonresponders in the initial 8-week trial were enrolled in an additional 4 months of openlabel treatment to determine whether the short-term efficacy and safety of risperidone were maintained. In the 51 subjects who completed the 16-week extension, the mean $\mathrm{ABC}$-Irritability score showed a $59 \%$ reduction from the mean baseline rating, which was consistent with the results of the initial short-term RUPP study. Fifty-two subjects (82.5\%) were rated as much improved or very much improved on the CGI-I at the completion of the open-label phase. Finally, 32 youth were enrolled in a placebo-controlled 8-week discontinuation study, which resulted in the return of aggression, SIB, and tantrums in $62.5 \%$ of individuals treated with placebo versus $12.5 \%$ of those remaining on risperidone.

Adverse effects in the above detailed risperidone studies included weight gain and somnolence/sedation. No study showed a significant difference in rates of EPS with risperidone treatment. Risperidone was generally well tolerated, and side effects were manageable by dosage and dosing schedule modifications. Following these positive results, the FDA approved risperidone as a treatment for irritability associated with autism in children and adolescents aged $5-16$ years old. ${ }^{48}$

In 2015, RUPP published the results of an additional 21-month follow-up study to the original 8-week controlled trial. ${ }^{53}$ Eighty-four subjects participated in the follow-up study; $56(66.7 \%)$ of these subjects continued risperidone treatment after the original study and were taking risperidone (mean dose: $2.47 \mathrm{mg} / \mathrm{d}$ ) in the month leading up to the follow-up appointment. Although uncontrolled and naturalistic, the high rate of continued use suggests therapeutic benefits as perceived by caregivers and clinicians. Improvement in targeted symptoms of irritability/aggression were associated with current risperidone exposure, as seen by reduced $\mathrm{ABC}$-Irritability scores $(P=0.01)$. There were no significant changes in complete blood count, lipid and glucose levels, urinalysis, or electrocardiogram. Although risperidone appears effective for up to 21 months of treatment, weight gain, excessive appetite, and enuresis were common adverse effects and pose a challenge to long-term treatment adherence and safety.

\section{Aripiprazole}

Aripiprazole has a unique mechanism of action as a partial $\mathrm{D}_{2}$ receptor and $5-\mathrm{HT}_{1 \mathrm{~A}}$ receptor agonist, and a $5-\mathrm{HT}_{2 \mathrm{~A}}$ receptor antagonist. Aripiprazole appears to differentially act as an agonist or antagonist depending on local dopamine concentrations. ${ }^{54}$ Following risperidone, aripiprazole was the 
second medication approved by the FDA to treat irritability and aggression in individuals with ASD, aged 6-17 years old. ${ }^{48}$ Aripiprazole has been studied extensively in ASD, with numerous reports demonstrating its efficacy.

A 2004 case series describes five subjects (5-18 years) with ASD and irritability. ${ }^{55}$ In this report, all five were rated as "much improved" or "very much improved" on the CGI-I after being treated with aripiprazole for at least 8 weeks. In a retrospective chart review of 32 patients aged 5-19 years old treated with aripiprazole (mean dose: $10.5 \mathrm{mg} / \mathrm{d}$ ) published in 2006, only nine individuals (37\%) of the 24 diagnosed with ASD showed improvement. ${ }^{56}$ Significant weight gain and sleepiness were common in this review.

In 2009, a 14-week open-label, prospective study of aripiprazole was conducted in 25 subjects aged 5-17 years old with ASD and significant irritability. ${ }^{57}$ Following 4 weeks of titration, the dose $(2.5-15 \mathrm{mg} / \mathrm{d}$, mean: $7.8 \mathrm{mg} / \mathrm{d})$ was maintained for 8 weeks. Twenty-two subjects $(88 \%)$ responded to treatment based on significant improvements on the CGI-I and ABC-I. Many subjects experienced weight gain, and EPS was reported in nine of 25 subjects. There were no changes in lipid levels, and serum prolactin declined.

Also in 2009, the first large-scale, 8-week placebocontrolled trial of aripiprazole in youth aged 6-17 years with ASD and significant irritability was completed. ${ }^{58}$ Of 218 subjects enrolled, $178(82 \%)$ completed the trial. Subjects were randomly assigned to fixed doses of 5,10 , and $15 \mathrm{mg} / \mathrm{d}$ or placebo. All doses of aripiprazole resulted in significant improvement in ABC-I scores compared to placebo (all $P$-values $<0.05)$. All treatment groups experienced significant weight gain. Sedation was common, and $22 \%-23 \%$ of subjects experienced EPS compared to $11.8 \%$ of subjects in the placebo group. Discontinuation rates due to adverse effects were $9.5 \%$ for $5 \mathrm{mg} / \mathrm{d}, 13.6 \%$ for $10 \mathrm{mg} / \mathrm{d}, 7.4 \%$ for $15 \mathrm{mg} / \mathrm{d}$, and $7.7 \%$ for placebo.

The second multisite, double-blind, placebo-controlled trial employed flexible dosing of aripiprazole. ${ }^{47}$ Ninety-eight subjects with ASD aged 6-17 years old were treated with aripiprazole for 8 weeks. Dosing at week 8 ranged from 2 to $15 \mathrm{mg} / \mathrm{d}(2 \mathrm{mg} / \mathrm{d}, \mathrm{n}=2 ; 5 \mathrm{mg} / \mathrm{d}, \mathrm{n}=13 ; 10 \mathrm{mg} / \mathrm{d}, \mathrm{n}=16 ; 15 \mathrm{mg} / \mathrm{d}$, $\mathrm{n}=8$ ). At week 8, 52.2\% of subjects showed a response based on the CGI-I and ABC-I, and the placebo response was lower than in the previous trial. On the basis of the CGI-I alone, $67 \%$ of subjects taking aripiprazole were much or very much improved, compared to $16 \%$ on placebo. Significant weight gain was common, and mean serum prolactin decreased.

As a follow-up to the two large trials, Marcus et al ${ }^{59}$ conducted a 52-week open-label extension trial to assess longer-term safety and tolerability of aripiprazole. Subjects included both those from the previous trials and subjects from new sites. Aripiprazole was flexibly dosed with a mean dosage of $10.6 \mathrm{mg} / \mathrm{d}$ for an average of 44.1 weeks. All subjects were diagnosed with ASD, but de novo subjects did not have a minimum requirement for baseline irritability. Of the 330 subjects enrolled, 199 (60.3\%) completed the trial. Subjects on placebo during the acute trial and de novo subjects showed significant improvements on the CGI-I and ABC-I. Improvements made by subjects in the treatment arms of the 8-week trials were maintained. Weight gain, increased appetite, vomiting, and insomnia were the most common adverse effects, and $10.6 \%$ of subjects discontinued because of adverse effects.

Study results suggest that aripiprazole is effective for reducing ASD-associated irritability in individuals aged 6-17 years old for up to 52 weeks, although treatment may be limited in some patients by significant weight gain, higher rates of EPS, and sedation. Aripiprazole is also not associated with prolonged corrected QT (QTc) interval, ${ }^{60}$ and prolactin levels decline with treatment. ${ }^{47,57}$

\section{Clozapine}

Clozapine was the first approved SGA in the US and is an approved therapy for treatment-resistant bipolar disorder and schizophrenia. ${ }^{61,62}$ Clozapine acts as a mild antagonist at $\mathrm{D}_{2}$ receptors, with additional actions at serotonin, histamine, and noradrenergic receptors. Rapid titration of clozapine has recently been shown to be safe and effective for the treatment of drug-refractory bipolar disorder and schizophrenia. ${ }^{63-65}$ Likewise, several case reports demonstrate its safety and effectiveness in reducing aggression in ASD. ${ }^{66-68}$ In 2011, Beherec et al ${ }^{69}$ reviewed the charts of six individuals with ASD (mean age: 23.2 \pm 6.9 years) treated with clozapine for aggressive behavior. Clozapine treatment was associated with a twofold reduction in aggressive behaviors and resulted in the reduction of number and dose of concomitant psychotropic medications prescribed. Subjects reported no extrapyramidal side effects, and no cases of agranulocytosis occurred. Adverse effects included constipation $(n=5)$, significant weight gain (most patients), and tachycardia $(n=1)$.

Despite evidence of effectiveness as a treatment for aggression, particularly to rapidly control symptoms, there have been no controlled studies of clozapine in individuals with developmental disability. ${ }^{70}$ Clozapine carries the potential for severe adverse effects, including cardiomyopathy, lowered seizure threshold, and agranulocytosis. ${ }^{71}$ In particular, agranulocytosis is life-threatening and requires frequent 
blood draws to monitor white blood cell counts. Because blood draws can be especially difficult in highly irritable or aggressive individuals with ASD, clozapine is rarely used in this population.

\section{Olanzapine}

Olanzapine is an SGA that acts as an antagonist at both $\mathrm{D}_{2}$ and 5- $\mathrm{HT}_{2 \mathrm{~A}}$ receptors, and is a first-line, FDA-approved treatment for schizophrenia. ${ }^{48}$ In 1997 , Horrigan et $\mathrm{al}^{72}$ wrote a letter to the editor of the Journal of the American Academy of Child and Adolescent Psychiatry containing two case reports suggesting olanzapine as an effective treatment for aggression and hyperactivity in ASD. Since then, several small studies and case reports have examined olanzapine as a treatment for ASD.

One double-blind, placebo-controlled trial has studied olanzapine in ASD. Eleven subjects enrolled and eight completed 8 weeks of treatment (two withdrew because of noncompliance and one from parental disagreement regarding study participation). ${ }^{73}$ Dose of olanzapine ranged from 7.5 to $12.5 \mathrm{mg} / \mathrm{d}$ (mean $=10 \pm 2.4 \mathrm{mg} / \mathrm{d}$ ). Olanzapine did not reduce symptoms measured by the Children Yale-Brown Obsessive Compulsive Scale ( $z=0.284, P=0.777$ ), the Overt Aggression Scale Modified (OAS-M) irritability measure $(z=0.985, P=0.325)$, or the OAS-M aggression measure $(z=0.424, P=0.671)$. However, the CGI-I rating scale showed a significant improvement in global functioning compared to placebo. The most common side effects were significant weight gain and sedation. No subjects developed EPS or dyskinesia.

A 12-week, open-label trial in four adolescents and four adults with ASD showed significant improvement on the CGI-I as well as aggressive symptoms on the SIB-Q. The average dose was $7.8 \pm 4.7 \mathrm{mg} / \mathrm{d}$ (range, $5-20 \mathrm{mg} / \mathrm{d}$ ). ${ }^{74}$ Adverse effects included significant weight gain and sedation. One subject withdrew from the study because their guardians felt that the subject's weight gain took priority over clinical improvement. On the contrary, another 12-week, open-label trial in 25 subjects demonstrated minimal clinical effects with olanzapine treatment and significant weight gain. ${ }^{75}$ A more recent 13-week open-label study of olanzapine took place in 40 adolescents diagnosed with ASD. ${ }^{76}$ Compared to baseline scores, 13-week scores showed significant improvement on all subscales of the ABC. Olanzapine was well tolerated and, interestingly, the study did not show significant weight gain with treatment.

Studies of olanzapine as a treatment of aggression in ASD show mixed results, but generally suggest that it may be somewhat effective. Olanzapine appears relatively safe and well tolerated, with significant weight gain and sedation as the most common side effects. The aforementioned studies did not report any cases of EPS or tardive dyskinesia.

\section{Quetiapine}

Quetiapine is an SGA that functions as a dopamine, serotonin, and adrenergic antagonist and was FDA approved for the treatment of schizophrenia in 1997. In ASD, doubleblind, placebo-controlled trials of quetiapine are lacking, but several open-label studies and case series have been completed. In a small open-label study, six children aged 6-15 years old with ASD were treated with quetiapine for 16 weeks. ${ }^{77}$ The mean dose was $225 \mathrm{mg} / \mathrm{d}$. Four of the subjects withdrew: three from sedation and one from a seizure. The two subjects who completed the 16 weeks of treatment were deemed responders on the CGI-I, but the authors concluded that quetiapine was poorly tolerated and generally not effective in the study. Side effects also included increased appetite and weight gain.

Another open-label study in nine adolescents, aged 12-17 years old, with ASD looked at quetiapine treatment for 12 weeks. ${ }^{78}$ The mean dose was $292 \mathrm{mg} / \mathrm{d}$. Six subjects completed the trial, and two were considered responders based on the CGI-I. Two subjects discontinued because of agitation/aggression and sedation, respectively. Weight gain was the most significant side effect.

Although the open-label studies do not demonstrate quetiapine as being particularly effective in ASD, two retrospective studies provide evidence that suggests otherwise. In the first case series, 20 patients aged 5-28 years old were treated clinically with quetiapine for 4-180 weeks (mean treatment length: 60 weeks) at an average dose of $249 \mathrm{mg} / \mathrm{d} .{ }^{79}$ On the CGI-I, eight (40\%) subjects were positive responders. Fifty percent of subjects experienced adverse effects, but only $15 \%$ of patients discontinued quetiapine treatment because of adverse effects. The second case series examined ten patients aged 5-19 years old. ${ }^{80}$ A mean dose of $477 \mathrm{mg} / \mathrm{d}$ was effective for six of the ten patients based on the CGI-I. The Conners Parent Rating Scale also showed improvement on the Conduct, Hyperactivity, and Inattention subscales. Adverse events included mild sedation, sialorrhea, and weight gain.

These open-label studies demonstrated global improvement rather than improved aggression symptoms, and the response rates reported with quetiapine are notably lower than risperidone rates. Nevertheless, quetiapine may still be of some benefit to individuals with ASD and aggression. 
Double-blind, placebo-controlled studies of quetiapine are needed to better understand its efficacy, side effects, and optimal dosing.

\section{Ziprasidone}

Ziprasidone is an FDA-approved SGA for the treatment of schizophrenia and acute mania associated with bipolar disorder. To date, no randomized, placebo-controlled trials have studied ziprasidone in subjects with ASD. However, several open-label trials, case reports, and retrospective studies suggest that it may be a weight-neutral treatment option for ASD-associated irritability symptoms.

Two case reports of young males with ASD that were nonresponsive to other medications, including risperidone, guanfacine, amphetamine salts, sertraline, and valproic acid (VPA), improved with ziprasidone. ${ }^{81,82} \mathrm{~A}$ case series of ten children and adolescents and two young adults with ASD demonstrated a $50 \%$ treatment response as measured by the CGI-I. ${ }^{83}$ The mean dose in this study was $59.23 \mathrm{mg} / \mathrm{d}$ (range: $20-120 \mathrm{mg} / \mathrm{d}$ ). Five subjects lost weight, five subjects had no change in weight, and one subject gained weight. The weight loss in five subjects was likely weight previously gained on other atypical antipsychotics. The most common adverse effect was sedation. In a 6-week open-label trial of ziprasidone in subjects with ASD (mean dose: $98.3 \mathrm{mg} / \mathrm{d}$ ), nine of twelve subjects (75\%) were treatment responders on the CGI-I and there was no weight gain reported ${ }^{84} \mathrm{~A}$ retrospective study looked at 42 subjects aged 5.97-18.67 years old (mean age: 11.8 years) treated with ziprasidone between 2004 and $2012 .{ }^{85}$ The mean treatment period was 10.8 months with a dose range of $20-240 \mathrm{mg} / \mathrm{d}$. Seventeen $(40 \%)$ subjects responded to treatment, and the body mass index $z$-score did not change in these participants with ziprasidone treatment.

A known risk of ziprasidone treatment is prolongation of cardiac QTc, which is associated with potentially fatal ventricular arrhythmia. Changes in heart rate and QTc interval have also been reported in children treated with low dose ziprasidone. ${ }^{86}$ In the retrospective study, no prolonged QTc intervals were reported in the nine subjects who received an electrocardiogram, although analysis was limited by the small sample size. ${ }^{85}$

Unlike other atypical antipsychotics, ziprasidone does not appear to cause weight gain and shows some efficacy for individuals with ASD and aggression. Therefore, it may be an effective treatment option in those for whom weight gain poses a serious health risk. All patients treated with ziprasidone should be monitored for QTc interval changes and cardiac events.

\section{Paliperidone}

Paliperidone, the major active metabolite of risperidone, is FDA approved for the treatment of schizophrenia in adults. ${ }^{48}$ Unlike other antipsychotics, delivery of the drug is controlled for up to 24 hours using the osmotic controlled release system technology, so it only requires once-daily dosing. ${ }^{87}$ No randomized, placebo-controlled studies of paliperidone have been completed in individuals with ASD, but two case reports and an open-label study suggest that it may be effective for treating aggression and that it is generally well tolerated in the population.

The first case report described a 20-year-old male with ASD and severe aggression and SIB who had not responded to treatment with haloperidol, quetiapine, lithium, chlorpromazine, fluvoxamine, or mirtazapine. ${ }^{88}$ After 7 months of continued SIB while on a regimen of risperidone, guanfacine, and VPA, the $8 \mathrm{mg} / \mathrm{d}$ of risperidone was changed to $12 \mathrm{mg} / \mathrm{d}$ of paliperidone while the other medications were maintained. The subject had a significant decrease in aggression, SIB, and tantrums, a "much improved" rating on the CGI-I, and no reported adverse effects. The second case report described a 16-year-old female with ASD and intermittent explosive disorder. She had previously tried quetiapine, risperidone, aripiprazole, and VPA with no improvement. While on a regimen of risperidone, naltrexone, and diazepam, she switched from risperidone to $6 \mathrm{mg}$ of paliperidone. Following the change, the subject was rated as "very much improved" on the CGI-I, and tolerated discontinuation of concomitant psychotropic medications. At the time the report was published, the subject had been maintained on $6 \mathrm{mg} / \mathrm{d}$ of paliperidone for 50 weeks with no adverse effects.

In an 8-week open-label trial of paliperidone in 25 subjects with ASD and irritability aged 12-21 years old, $21(84 \%)$ were deemed "much improved" or "very much improved" on the CGI-I and had $\geq 25 \%$ improvement on the ABC-I. ${ }^{89}$ The mean paliperidone dose was $7.1 \mathrm{mg} / \mathrm{d}$ (range: $3-12 \mathrm{mg} / \mathrm{d}$ ). Two subjects discontinued: one because of moderate sedation and one because of lack of response. Four subjects experienced mild-to-moderate EPS. Twenty (80\%) subjects experienced weight gain and a significant increase in prolactin levels. It is important to note that 21 of the subjects had previously been on risperidone either immediately before the study or at an earlier time. Twenty of this subset had discontinued risperidone because of nonresponse, but all of them responded to paliperidone. Although limited, evidence suggests that paliperidone may be effective and well tolerated for treating aggression in ASD and could provide an alternative treatment option for patients who do not respond to risperidone. Double-blind, randomized, placebo-controlled 
trials are needed to further understand the effectiveness of paliperidone in ASD.

\section{Lurasidone}

The SGA lurasidone targets both $\mathrm{D}_{2}$ and $5-\mathrm{HT}_{2 \mathrm{~A}}$ receptors and was FDA approved for the treatment of schizophrenia in adults in 2010. Lurasidone was recently studied in a multicenter, double-blind, placebo-controlled trial targeting irritability in youth with ASD.${ }^{90}$ One hundred fifty individuals aged 6-17 years were randomized to 6 weeks of treatment with low-dose lurasidone $(20 \mathrm{mg} / \mathrm{d})$, high-dose lurasidone $(60 \mathrm{mg} / \mathrm{d})$, or placebo. There was no statistically significant improvement in either active treatment group or placebo on the ABC-I ( $P=0.55$ and $P=0.36$, respectively). Rates of adverse effects were higher in the active treatment groups, with reported incidents of vomiting and somnolence. This study of lurasidone is the first large-scale negative trial of an SGA targeting irritability in ASD, suggesting that lurasidone is not a viable treatment option for this target symptom cluster.

\section{First-generation antipsychotics}

\section{Haloperidol}

Haloperidol is the only first-generation antipsychotic with significant evidence to support its use in youth with ASD. Although other first-generation antipsychotics are also potent dopamine antagonists, haloperidol is associated with fewer adverse cognitive effects, less sedation, and fewer EPS. ${ }^{91}$ Based on this information, haloperidol was chosen for the first placebo-controlled investigations of antipsychotics in children with ASD. These initial studies did not focus on aggression specifically, but rather described significant improvement in withdrawal and stereotypy in children with ASD, and additionally demonstrated positive impact on learning when haloperidol treatment was combined with language training. ${ }^{92-94}$ Sedation and acute dystonic reactions were common. Although haloperidol has been shown to have long-term safety and efficacy, ${ }^{95}$ it is associated with a significant risk of dyskinesias. In a prospective study of tardive and withdrawal dyskinesias, 118 children with ASD were treated for cycles of 6 months of haloperidol plus 4 weeks of placebo. ${ }^{96}$ Forty (33.9\%) subjects developed dyskinesias. Most were withdrawal dyskinesias, and all were reversible. In a subgroup of ten subjects who received a higher average dose, nine (90\%) subjects developed dyskinesias.

\section{Nonantipsychotic medications}

\section{Antiepileptic medications}

AEDs are frequently prescribed off-label in youth with ASD targeting irritability symptoms. A 2014 systematic review identified seven randomized, placebo-controlled trials of AEDs in ASD (total $n=171$ ), including four studies of VPA, one of lamotrigine, one of topiramate, and one of levetiracetam. ${ }^{97}$ A meta-analysis of these studies revealed no significant improvement with AED administration in the treatment of irritability symptoms (four studies) or targeting global improvement (three studies), although rate of discontinuation was not different between AED and placebo groups across studies.

VPA in particular has been of interest in ASD psychopharmacology based on significant evidence in the adult psychiatric literature, which suggests that the medication is effective for the treatment of aggressive and impulsive behaviors. ${ }^{98}$ Hellings et al ${ }^{99}$ completed a double-blind, placebo-controlled trial of VPA targeting aggressive behavior in youth with ASD. In this study, 30 individuals with ASD aged 6-20 years received treatment with VPA $(n=16)$ or placebo $(n=14)$ for 8 weeks. Five subjects withdrew from the study because of severe aggression $(n=4)$ or rash $(n=1)$. Mean VPA level at week 8 was $77.7 \mu \mathrm{g} / \mathrm{dL}$ (range: 58.6-101.1). There was no statistically significant improvement reported with VPA treatment on the ABC-I primary outcome measure $(P=0.65)$. Reported adverse effects included skin rash, weight gain, elevated ammonia levels, cognitive slowing, and gastrointestinal adverse effects. Investigators concluded that VPA does not appear to be a viable treatment option for youth with ASD and irritability; however, larger controlled trials may be indicated.

\section{Lithium}

Lithium is one of the oldest medications employed for the treatment for psychiatric symptoms, with reports of its use dating back to the 19th century. Lithium is indicated for the treatment of bipolar disorder and has demonstrated efficacy for decreasing suicide in individuals with affective disorders. ${ }^{100}$ Despite its extensive psychiatric history, lithium has been studied only peripherally in ASD. In 1972, a controlled crossover trial of lithium and chlorpromazine in ten "severely disturbed" children aged 3-6 years (including one child with ASD) demonstrated improvement in hyperactivity and aggressive behavior, although results were nonsignificant. ${ }^{101}$ Two subsequent case reports describe symptomatic improvement with lithium treatment in individuals with mania-like symptoms and ASD. ${ }^{102,103}$ In 2014, Siegel et al ${ }^{104}$ published a retrospective review of lithium treatment in 30 children diagnosed with ASD. In this review, $43 \%$ of all included participants treated with lithium had scores of "very much improved" or "much improved" on the CGI-I primary outcome measure. Seventy-one percent of children with two 
or more pretreatment affective disorder symptoms (ie, mania or euphoric mood) were rated as "improved". However, significant adverse effects were reported, including vomiting $(13 \%)$, tremor $(10 \%)$, fatigue $(0 \%)$, irritability $(7 \%)$, and enuresis $(7 \%)$. Lithium may warrant future investigation in controlled trials targeting ASD-associated aggression; however, adverse effects with lithium are common and may be a limiting factor.

\section{$\mathrm{N}$-acetylcysteine}

$\mathrm{N}$-acetylcysteine (NAC) is a unique antioxidant historically used as a mucolytic, a renal protectant, and as a treatment for acetaminophen overdose. ${ }^{105}$ NAC helps regulate extracellular glutamate levels and is a component of the potent antioxidant glutathione. ${ }^{106}$ Recently, NAC has been studied in ASD, as its functions overlap with proposed mechanisms of ASD pathophysiology. ${ }^{107,108}$ In 2012, Hardan et al ${ }^{109}$ completed a placebo-controlled pilot study of NAC in 29 youth aged 3.2-10.7 years with ASD. This study reported significant reduction in irritability symptoms as measured by the ABC-I. NAC was reportedly well tolerated, with minimal associated gastrointestinal symptoms reported. Two small double-blind placebo-controlled studies of NAC treatment in conjunction with risperidone targeting irritability in youth with ASD showed significant reduction in ABC-I scores. ${ }^{110,111}$ Future larger controlled studies of NAC alone or as an adjunct to SGA treatment targeting ASD-associated irritability are warranted.

\section{Naltrexone}

Naltrexone is an opiate-receptor antagonist FDA-approved for the treatment of alcohol and opioid dependence. Reports suggest that disturbance of the opioid system may be implicated in individuals with SIBs and potentially in producing the core social impairments of ASD. ${ }^{12,113}$ Naltrexone has been studied in ten randomized, placebo-controlled trials in ASD targeting core symptoms, hyperactivity, self-injury, and irritability. The largest study completed by Campbell et $\mathrm{al}^{114}$ enrolled 41 children with ASD aged 2.9-7.8 years. In this study, participants received naltrexone or matching placebo for 3 weeks, with resultant significant improvement in hyperactivity symptoms in the naltrexone groups $(P=0.00002)$ as captured by the Children's Psychiatric Rating Scale (CPRS). However, no significant symptomatic improvement was noted in core features of ASD or rates of self-injury. In 2014 , Roy et al ${ }^{115}$ completed a systematic review of the naltrexone literature in ASD. The authors concluded that naltrexone may have a positive impact on reducing hyperactivity and restlessness in children with ASD, but also state that naltrexone is unlikely to improve core features of ASD. Naltrexone does not appear to have robust effects targeting ASD-associated aggression, although it may have some impact on hyperactivity symptoms in this population.

\section{Pharmacologic management of refractory aggression}

Aggressive behavior that does not respond to first-line psychopharmacologic treatments is a significant concern for a subpopulation of individuals with ASD. A retrospective review of the medical records of 135 individuals with ASD treated at an ASD-specialized psychiatry clinic demonstrated that a significant proportion of individuals $(n=53,39.5 \%)$ met criteria for drug refractory behaviors (defined as aggression, self-injury, and tantrums remaining as the primary target of treatment despite trials of risperidone and aripiprazole or three or more psychotropic drugs targeting irritability). ${ }^{116}$ Despite these concerns, to date there are no guidelines for the treatment of refractory ASD-associated aggression.

Emerging evidence has demonstrated increasing frequency of concomitant antipsychotic use for the treatment of behavioral symptoms in individuals with ASD. ${ }^{117}$ A recent study by Wink et al $^{118}$ identified combination antipsychotic treatment as a potential option for patients with ASD and severe behavioral symptoms. In this review, $6.4 \%$ of individuals included in a 1,100-patient longitudinal medication management database received combination antipsychotic therapy. This treatment modality was relatively well tolerated by participants; however, the report was lacking in consistent use of standardized measures of clinical improvement and medical evaluations. Clearly, safety of concomitant antipsychotic use is a significant concern, particularly in children. To date, no ASD specific information on the safety of combination antipsychotic therapy is available. Reports in the general psychiatric literature demonstrate increased rates of adverse effects with combination antipsychotic therapy. ${ }^{119}$

Faced with this formidable challenge, investigators are turning to more novel mechanisms for the treatment of ASD-associated aggression such as glutamatergic agents and gamma-aminobutyric acid modulators. Amantadine, memantine, riluzole, and arbaclofen have shown promise in preliminary studies of disruptive behaviors in ASD, but there remains a clear need for additional investigation targeting refractory aggression in ASD. ${ }^{120-125}$

\section{Conclusion}

Aggressive behavior is a significant concern with demonstrated negative impact on the quality of life for individuals 
with ASD and their caregivers. Behavioral challenges often place individuals with ASD and caregivers at risk of physical injury and limit the efficacy of therapeutic, educational, and vocational interventions. ${ }^{126,127}$ Pharmacologic treatments, particularly the use of SGAs, may reduce aggressive behaviors in some individuals with ASD. Despite the common use of pharmacotherapy to target these behaviors, the neurobiological underpinnings of these behaviors in the context of ASD remain poorly understood. The development of putative murine or other translational models of ASD that present the core impairments of the disorder - social and communication impairment combined with repetitive behavior - and aggressive behavior may assist efforts to develop true targeted treatments of ASD-associated aggression. To date, drug treatment approaches for ASD have borrowed from success in other fields of neuropsychiatry and are not targeted against the neurobiological mechanisms that drive the interfering behaviors.

Beyond drug treatment, therapeutic behavioral strategies including functional behavioral assessment, reinforcement strategies, and FCT are demonstrated to have significant impact in reducing the frequency and intensity of aggressive behavior in individuals with ASD. With the ever-increasing rate of ASD diagnosis, ${ }^{128}$ development of effective therapeutic and pharmacologic methods for preventing and treating aggression are essential to improving the outcomes in this disorder. Future research must incorporate both modalities, similar to recent work targeting core features of ASD. ${ }^{129}$ An evidence base supporting combined medication plus therapy approach for the treatment of ASD-associated aggression is greatly needed. In addition, development of evidence-based treatment algorithms for individuals refractory to first-line pharmacologic treatments is imperative.

\section{Disclosure}

The authors report no conflicts of interest in this work.

\section{References}

1. American Psychiatric Association. Diagnostic and Statistical Manual of Mental Disorders: DSM-5. Spring Hill, TN: ManMag; 2003.

2. Hastings RP, Kovshoff H, Ward NJ, degli Espinosa F, Brown T, Remington B. Systems analysis of stress and positive perceptions in mothers and fathers of pre-school children with autism. J Autism Dev Disord. 2005;35(5):635-644.

3. Lecavalier L, Leone S, Wiltz J. The impact of behaviour problems on caregiver stress in young people with autism spectrum disorders. J Intellect Disabil Res. 2006;50(3):172-183.

4. Aman M, Singh N. Aberrant Behavior Checklist: Manual. East Aurora, NY: Slosson Educational Publications; 1986.

5. Kaartinen M, Puura K, Helminen M, Salmelin R, Pelkonen E, Juujärvi P. Reactive aggression among children with and without autism spectrum disorder. J Autism Dev Disord. 2014;44(10):2383-2391.
6. Farmer C, Butter E, Mazurek MO, et al. Aggression in children with autism spectrum disorders and a clinic-referred comparison group. Autism. 2015;19(3):281-291.

7. Hartley S, Sikora D, McCoy R. Prevalence and risk factors of maladaptive behaviour in young children with autistic disorder. J Intellect Disabil Res. 2008;52(10):819-829.

8. Love JR, Carr JE, LeBlanc LA. Functional assessment of problem behavior in children with autism spectrum disorders: a summary of 32 outpatient cases. J Autism Dev Disord. 2009;39(2):363-372.

9. McClintock K, Hall S, Oliver C. Risk markers associated with challenging behaviours in people with intellectual disabilities: a meta-analytic study. J Intellect Disabil Res. 2003;47(6):405-416.

10. Tsakanikos E, Costello H, Holt G, Sturmey P, Bouras N. Behaviour management problems as predictors of psychotropic medication and use of psychiatric services in adults with autism. J Autism Dev Disord. 2007;37(6):1080-1085.

11. Kanne SM, Mazurek MO. Aggression in children and adolescents with ASD: prevalence and risk factors. J Autism Dev Disord. 2011; 41(7):926-937.

12. Matson JL, Rivet TT. The effects of severity of autism and PDD-NOS symptoms on challenging behaviors in adults with intellectual disabilities. J Dev Phys Disabil. 2008;20(1):41-51.

13. NICHD Early Child Care Research Network. Trajectories of physical aggression from toddlerhood to middle childhood: predictors, correlates, and outcomes. Monogr Soc Res Child Dev. 2004;69(4):vii, 1-129.

14. Eisenhower AS, Baker BL, Blacher J. Preschool children with intellectual disability: syndrome specificity, behaviour problems, and maternal well-being. J Intellect Disabil Res. 2005;49(9):657-671.

15. Reese RM, Richman DM, Belmont JM, Morse P. Functional characteristics of disruptive behavior in developmentally disabled children with and without autism. J Autism Dev Disord. 2005;35(4):419-428.

16. Dominick KC, Davis NO, Lainhart J, Tager-Flusberg H, Folstein S. Atypical behaviors in children with autism and children with a history of language impairment. Res Dev Disabil. 2007;28(2):145-162.

17. Luiselli JK. Aggression and noncompliance. In: Applied Behavior Analysis for Children with Autism Spectrum Disorders. Berlin, Germany: Springer; 2009:175-187.

18. Dryden-Edwards RC, Combrinck-Graham L. Developmental Disabilities from Childhood to Adulthood: What Works for Psychiatrists in Community and Institutional Settings. Baltimore, MD: JHU Press; 2010.

19. Dagnan D, Weston C. Physical intervention with people with intellectual disabilities: the influence of cognitive and emotional variables. $J \mathrm{Appl}$ Res Intellect Disabil. 2006;19(2):219-222.

20. Stith SM, Liu T, Davies LC, et al. Risk factors in child maltreatment: a meta-analytic review of the literature. Aggress Violent Behav. 2009;14(1):13-29.

21. Otero-López JM, Castro C, Villardefrancos E, Santiago MJ. Job dissatisfaction and burnout in secondary school teachers: student's disruptive behaviour and conflict management examined. Eur J Educ Psychol. 2009;2(2):99-111.

22. Neece CL, Green SA, Baker BL. Parenting stress and child behavior problems: a transactional relationship across time. Am J Intellect Dev Disabil. 2012;117(1):48-66.

23. Hodgetts S, Nicholas D, Zwaigenbaum L. Home sweet home? Families' experiences with aggression in children with autism spectrum disorders. Focus Autism Dev Disabil. 2013;28(3):166-174.

24. Powers MD, Palmieri MJ, D’Eramo KS, Powers KM. Evidence-based treatment of behavioral excesses and deficits for individuals with autism spectrum disorders. In: Evidence-based Practices and Treatments for Children with Autism. New York, NY: Springer; 2011:55-92.

25. Soorya L, Carpenter L, Romanczyk R. Applied behavior analysis. Textbook of Autism Spectrum Disorders. Arlington, VA: American Psychiatric Publishing; 2011:525-536.

26. Cooper JO, Heron TE, Heward WL. Applied Behavior Analysis. 2nd ed. New York, NY: Pearson; 2007.

27. Wong C, Odom SL, Hume KA, et al. Evidence-based practices for children, youth, and young adults with autism spectrum disorder: a comprehensive review. J Autism Dev Disord. 2015;45(7):1951-1966. 
28. Roth ME, Gillis JM, Reed FD. A meta-analysis of behavioral interventions for adolescents and adults with autism spectrum disorders. J Behav Educ. 2014;23(2):258-286.

29. Iwata BA, Dorsey MF, Slifer KJ, Bauman KE, Richman GS. Toward a functional analysis of self-injury. J Appl Behav Anal. 1994;27(2): 197.

30. Paclawskyj TR, Matson JL, Rush KS, Smalls Y, Vollmer TR. Questions about behavioral function (QABF): a behavioral checklist for functional assessment of aberrant behavior. Res Dev Disabil. 2000; 21(3):223-229.

31. Iwata BA, DeLeon IG, Roscoe EM. Reliability and validity of the functional analysis screening tool. J Appl Behav Anal. 2013;46(1): 271-284.

32. Newcomer LL, Lewis TJ. Functional behavioral assessment: an investigation of assessment reliability and effectiveness of function-based interventions. J Emot Behav Disord. 2004;12(3):168-181.

33. Herzinger CV, Campbell JM. Comparing functional assessment methodologies: a quantitative synthesis. J Autism Dev Disord. 2007;37(8): 1430-1445.

34. Badgett N, FalcomataTS. A comparison of methodologies of brief functional analysis. Dev Neurorehabil. 2015;18(4):224-233.

35. Querim AC, Iwata BA, Roscoe EM, Schlichenmeyer KJ, Ortega JV, Hurl KE. Functional analysis screening for problem behavior maintained by automatic reinforcement. J Appl Behav Anal. 2013;46(1):47-60.

36. Harding JW, Wacker DP, Berg WK, Lee JF, Dolezal D. Conducting functional communication training in home settings: a case study and recommendations for practitioners. Behav Anal Pract. 2009;2(1):21.

37. Ferster CB. Positive reinforcement and behavioral deficits of autistic children. Child Dev. 1961;32:437-456.

38. Matson JL, Dixon DR, Matson ML. Assessing and treating aggression in children and adolescents with developmental disabilities: a 20-year overview. Educ Psychol. 2005;25(2-3):151-181.

39. Gerhardt PF, Weiss MJ, Delmolino L. Treatment of severe aggression in an adolescent with autism: non-contingent reinforcement and functional communication training. Behav Anal Today. 2004;4(4):386.

40. Carr JE, Coriaty S, Wilder DA, et al. A review of "noncontingent" reinforcement as treatment for the aberrant behavior of individuals with developmental disabilities. Res Dev Disabil. 2000;21(5):377-391.

41. Carr EG, Durand VM. Reducing behavior problems through functional communication training. J Appl Behav Anal. 1985;18(2):111-126.

42. Braithwaite KL, Richdale AL. Functional communication training to replace challenging behaviors across two behavioral outcomes. Behav Interv. 2000;15(1):21-36.

43. Schieltz KM, Wacker DP, Harding JW, et al. Indirect effects of functional communication training on non-targeted disruptive behavior. J Behav Educ. 2011;20(1):15-32.

44. Kurtz PF, Boelter EW, Jarmolowicz DP, Chin MD, Hagopian LP. An analysis of functional communication training as an empirically supported treatment for problem behavior displayed by individuals with intellectual disabilities. Res Dev Disabil. 2011;32(6):2935-2942.

45. Blankenship K, Erickson CA, McDougle CJ. Pharmacotherapy of autism and related disorders. Psychiatr Ann. 2010;40(4):203-209.

46. McCracken JT, McGough J, Shah B, et al. Risperidone in children with autism and serious behavioral problems. $N$ Engl J Med. 2002; 347(5):314-321.

47. Owen R, Sikich L, Marcus RN, et al. Aripiprazole in the treatment of irritability in children and adolescents with autistic disorder. Pediatrics. 2009;124(6):1533-1540.

48. CenterWatch. Drug Information: FDA-Approved Drugs. Silver Spring, MD: US Food and Drug Administration; 2009. Available from: http://www.centerwatch.com/drug-information/fda-approved-drugs/ year/2009. Accessed April 26, 2016.

49. Horrigan JP, Barnhill LJ. Risperidone and explosive aggressive autism. J Autism Dev Disord. 1997;27(3):313-323.

50. McDougle CJ, Holmes JP, Carlson DC, Pelton GH, Cohen DJ, Price LH. A double-blind, placebo-controlled study of risperidone in adults with autistic disorder and other pervasive developmental disorders. Arch Gen Psychiatry. 1998;55(7):633-641.
51. Shea S, Turgay A, Carroll A, et al. Risperidone in the treatment of disruptive behavioral symptoms in children with autistic and other pervasive developmental disorders. Pediatrics. 2004;114(5):e634-e641.

52. Research Units on Pediatric Psychopharmacology Autism Network. Risperidone treatment of autistic disorder: longer-term benefits and blinded discontinuation after 6 months. Am J Psychiatry. 2005;162(7): 1361-1369.

53. Aman M, Rettiganti M, Nagaraja HN, et al. Tolerability, safety, and benefits of risperidone in children and adolescents with autism: 21-month follow-up after 8-week placebo-controlled trial. J Child Adolesc Psychopharmacol. 2015;25(6):482-493.

54. Erickson CA, Stigler KA, Posey DJ, McDougle CJ. Aripiprazole in autism spectrum disorders and fragile $\mathrm{X}$ syndrome. Neurotherapeutics. 2010;7(3):258-263.

55. Stigler KA, Posey DJ, McDougle CJ. Aripiprazole for maladaptive behavior in pervasive developmental disorders. J Child Adolesc Psychopharmacol. 2004;14(3):455-463.

56. Valicenti-McDermott MR, Demb H. Clinical effects and adverse reactions of off-label use of aripiprazole in children and adolescents with developmental disabilities. J Child Adolesc Psychopharmacol. 2006;16(5):549-560.

57. Stigler KA, Diener JT, Kohn AE, et al. Aripiprazole in pervasive developmental disorder not otherwise specified and Asperger's disorder: a 14-week, prospective, open-label study. J Child Adolesc Psychopharmacol. 2009;19(3):265-274.

58. Marcus RN, Owen R, Kamen L, et al. A placebo-controlled, fixeddose study of aripiprazole in children and adolescents with irritability associated with autistic disorder. J Am Acad Child Adolesc Psychiatry. 2009;48(11):1110-1119.

59. Marcus RN, Owen R, Manos G, et al. Aripiprazole in the treatment of irritability in pediatric patients (aged 6-17 years) with autistic disorder: results from a 52-week, open-label study. J Child Adolesc Psychopharmacol. 2011;21(3):229-236.

60. Ho JG, Caldwell RL, McDougle CJ, et al. The effects of aripiprazole on electrocardiography in children with pervasive developmental disorders. J Child Adolesc Psychopharmacol. 2012;22(4):277-283.

61. Lally J, MacCabe JH. Antipsychotic medication in schizophrenia: a review. Br Med Bull. 2015;114(1):169-179.

62. Li XB, Tang YL, Wang CY, de Leon J. Clozapine for treatment-resistant bipolar disorder: a systematic review. Bipolar Disord. 2015;17(3): 235-247.

63. Ifteni P, Correll CU, Nielsen J, Burtea V, Kane JM, Manu P. Rapid clozapine titration in treatment-refractory bipolar disorder. J Affect Disord. 2014;166:168-172.

64. Poyraz CA, Turan Ş, Demirel ÖF, Usta Sağlam NG, Yıldız N, Duran A. Effectiveness of ultra-rapid dose titration of clozapine for treatmentresistant bipolar mania: case series. Ther Adv Psychopharmacol. 2015: 5(4):237-242.

65. Poyraz CA, Özdemir A, Sağlam NG, et al. Rapid clozapine titration in patients with treatment refractory schizophrenia. Psychiatr Q. 2016; 87(2):315-322.

66. Chen NC, Bedair HS, McKay B, Bowers MB Jr, Mazure C. Clozapine in the treatment of aggression in an adolescent with autistic disorder. J Clin Psychiatry. 2001;62(6):479-480.

67. Gobbi G, Pulvirenti L. Long-term treatment with clozapine in an adult with autistic disorder accompanied by aggressive behaviour. J Psychiatry Neurosci. 2001;26(4):340-341.

68. Lambrey S, Falissard B, Martin-Barrero M, et al. Effectiveness of clozapine for the treatment of aggression in an adolescent with autistic disorder. J Child Adolesc Psychopharmacol. 2010;20(1):79-80.

69. Beherec L, Lambrey S, Quilici G, Rosier A, Falissard B, Guillin O. Retrospective review of clozapine in the treatment of patients with autism spectrum disorder and severe disruptive behaviors. J Clin Psychopharmacol. 2011;31(3):341-344.

70. Ayub M, Saeed K, Munshi TA, Naeem F. Clozapine for psychotic disorders in adults with intellectual disabilities. Cochrane Database Syst Rev. 2015;9:CD010625. 
71. Maayan L, Correll CU. Weight gain and metabolic risks associated with antipsychotic medications in children and adolescents. J Child Adolesc Psychopharmacol. 2011;21(6):517-535.

72. Horrigan JP, Barnhill LJ, Courvoisie HE. Olanzapine in PDD. J Am Acad Child Adolesc Psychiatry. 1997;36(9):1166-1167.

73. Hollander E, Wasserman S, Swanson EN, et al. A double-blind placebo-controlled pilot study of olanzapine in childhood/adolescent pervasive developmental disorder. J Child Adolesc Psychopharmacol. 2006;16(5):541-548.

74. Potenza MN, Holmes JP, Kanes SJ, McDougle CJ. Olanzapine treatment of children, adolescents, and adults with pervasive developmental disorders: an open-label pilot study. J Clin Psychopharmacol. 1999; 19(1):37-44

75. Kemner C, Willemsen-Swinkels SH, de Jonge M, Tuynman-Qua H, van Engeland H. Open-label study of olanzapine in children with pervasive developmental disorder. J Clin Psychopharmacol. 2002; 22(5):455-460.

76. Fido A, Al-Saad S. Olanzapine in the treatment of behavioral problems associated with autism: an open-label trial in Kuwait. Med Princ Pract. 2008;17(5):415-418.

77. Martin A, Koenig K, Scahill L, Bregman J. Open-label quetiapine in the treatment of children and adolescents with autistic disorder. JChild Adolesc Psychopharmacol. 1999;9(2):99-107.

78. Findling RL, McNamara NK, Gracious BL, et al. Quetiapine in nine youths with autistic disorder. J Child Adolesc Psychopharmacol. 2004; 14(2):287-294.

79. Corson AH, Barkenbus JE, Posey DJ, Stigler KA, McDougle CJ. A retrospective analysis of quetiapine in the treatment of pervasive developmental disorders. J Clin Psychiatry. 2004;65(11): 1531-1536.

80. Hardan AY, Jou RJ, Handen BL. Retrospective study of quetiapine in children and adolescents with pervasive developmental disorders. J Autism Dev Disord. 2005;35(3):387-391.

81. Goforth HW, Rao MS. Improvement in behaviour and attention in an autistic patient treated with ziprasidone. Aust N Z J Psychiatry. 2003; 37(6):775-776.

82. Duggal HS. Ziprasidone for maladaptive behavior and attention-deficit/ hyperactivity disorder symptoms in autistic disorder. J Child Adolesc Psychopharmacol. 2007;17(2):261-264

83. McDougle CJ, Kem DL, Posey DJ. Case series: use of ziprasidone for maladaptive symptoms in youths with autism. J Am Acad Child Adolesc Psychiatry. 2002;41(8):921-927.

84. Malone RP, Delaney MA, Hyman SB, Cater JR. Ziprasidone in adolescents with autism: an open-label pilot study. J Child Adolesc Psychopharmacol. 2007;17(6):779-790.

85. Dominick K, Wink LK, McDougle CJ, Erickson CA. A retrospective naturalistic study of ziprasidone for irritability in youth with autism spectrum disorder. J Child Adolesc Psychopharmacol. 2015; 25(5):397-401.

86. Taylor D. Ziprasidone in the management of schizophrenia. CNS Drugs. 2003;17(6):423-430

87. Karlsson P, Dencker E, Nyberg S. Pharmacokinetics, dopamine D2 and serotonin 5-HT2A receptor occupancy and safety profile of paliperidone ER, in healthy volunteers. Eur Neuropsychopharmacol. 2005; 15(Suppl 3):S38.

88. Stigler KA, Erickson CA, Mullett JE, Posey DJ, McDougle CJ. Paliperidone for irritability in autistic disorder. J Child Adolesc Psychopharmacol. 2010;20(1):75-78.

89. Stigler KA, Mullett JE, Erickson CA, Posey DJ, McDougle CJ. Paliperidone for irritability in adolescents and young adults with autistic disorder. Psychopharmacology (Berl). 2012;223(2):237-245.

90. Loebel A, Brams M, Goldman RS, et al. Lurasidone for the treatment of irritability associated with autistic disorder. J Autism Dev Disord. 2016;46(4):1153-1163.

91. Engelhardt DM, Polizos P, Waizer J, Hoffman SP. A double-blind comparison of fluphenazine and haloperidol in outpatient schizophrenic children. J Autism Child Schizophr. 1973;3(2):128-137.
92. Campbell M, Anderson LT, Meier M, et al. A comparison of haloperidol and behavior therapy and their interaction in autistic children. J Am Acad Child Psychiatry. 1978;17(4):640-655.

93. Campbell M, Anderson LT, Small AM, Perry R, Green WH, Caplan R. The effects of haloperidol on learning and behavior in autistic children. J Autism Dev Disord. 1982;12(2):167-175.

94. Anderson LT, Campbell M, Adams P, Small AM, Perry R, Shell J. The effects of haloperidol on discrimination learning and behavioral symptoms in autistic children. J Autism Dev Disord. 1989;19(2): 227-239.

95. Perry R, Campbell M, Adams P, et al. Long-term efficacy of haloperidol in autistic children: continuous versus discontinuous drug administration. J Am Acad Child Adolesc Psychiatry. 1989;28(1): 87-92.

96. Armenteros JL, Adams PB, Campbell M, Eisenberg ZW. Haloperidolrelated dyskinesias and pre- and perinatal complications in autistic children. Psychopharmacol Bull. 1995;31(2):363-369.

97. Hirota T, Veenstra-Vanderweele J, Hollander E, Kishi T. Antiepileptic medications in autism spectrum disorder: a systematic review and meta-analysis. J Autism Dev Disord. 2014;44(4):948-957.

98. Huband N, Ferriter M, Nathan R, Jones H. Antiepileptics for aggression and associated impulsivity. Cochrane Database Syst Rev. 2010; (2):CD003499.

99. Hellings JA, Weckbaugh M, Nickel EJ, et al. A double-blind, placebo-controlled study of valproate for aggression in youth with pervasive developmental disorders. J Child Adolesc Psychopharmacol. 2005;15(4):682-692.

100. Lewitzka U, Severus E, Bauer R, Ritter P, Müller-Oerlinghausen B, Bauer M. The suicide prevention effect of lithium: more than 20 years of evidence-a narrative review. Int J Bipolar Disord. 2015;3(1):32.

101. Campbell M, Fish B, Korein J, Shapiro T, Collins P, Koh C. Lithium and chlorpromazine: a controlled crossover study of hyperactive severely disturbed young children. J Autism Child Schizophr. 1972;2(3): 234-263.

102. Kerbeshian J, Burd L, Fisher W. Lithium carbonate in the treatment of two patients with infantile autism and atypical bipolar symptomatology. J Clin Psychopharmacol. 1987;7(6):401-405.

103. Steingard R, Biederman J. Lithium responsive manic-like symptoms in two individuals with autism and mental retardation. $J$ Am Acad Child Adolesc Psychiatry. 1987;26(6):932-935.

104. Siegel M, Beresford CA, Bunker M, et al. Preliminary investigation of lithium for mood disorder symptoms in children and adolescents with autism spectrum disorder. J Child Adolesc Psychopharmacol. 2014;24(7):399-402.

105. Deepmala, Slattery J, Kumar N, et al. Clinical trials of N-acetylcysteine in psychiatry and neurology: a systematic review. Neurosci Biobehav Rev. 2015;55:294-321.

106. Berk M, Malhi GS, Gray LJ, Dean OM. The promise of N-acetylcysteine in neuropsychiatry. Trends Pharmacol Sci. 2013;34(3):167-177.

107. James SJ, Melnyk S, Jernigan S, et al. Metabolic endophenotype and related genotypes are associated with oxidative stress in children with autism. Am J Med Genet B Neuropsychiatr Genet. 2006;141B(8): 947-956.

108. Erickson CA, McDougle CJ, Stigler KA, Posey DJ. Glutamatergic function in autism. In: Heresco-Levy U, editor. Glutamate in Neuropsychiatric Disorders. Trivandrum, Kerala: Research Signpost: 2008.

109. Hardan AY, Fung LK, Libove RA, et al. A randomized controlled pilot trial of oral N-acetylcysteine in children with autism. Biol Psychiatry. 2012;71(11):956-961.

110. Ghanizadeh A, Moghimi-Sarani E. A randomized double blind placebo controlled clinical trial of N-Acetylcysteine added to risperidone for treating autistic disorders. BMC Psychiatry. 2013;13:196.

111. Nikoo M, Radnia H, Farokhnia M, Mohammadi MR, Akhondzadeh S. $\mathrm{N}$-acetylcysteine as an adjunctive therapy to risperidone for treatment of irritability in autism: a randomized, double-blind, placebocontrolled clinical trial of efficacy and safety. Clin Neuropharmacol. 2015;38(1):11-17. 
112. Posey DJ, McDougle CJ. The pharmacotherapy of target symptoms associated with autistic disorder and other pervasive developmental disorders. Harv Rev Psychiatry. 2000;8(2):45-63.

113. Panksepp J, Sahley TL. Possible brain opioid involvement in disrupted social intent and language development of autism. In: Schopler E, Mesibov GB, editors. Neurobiological Issues in Autism. New York, NY: Plenum Press; 1987

114. Campbell M, Anderson LT, Small AM, et al. Naltrexone in autistic children: behavioral symptoms and attentional learning. J Am Acad Child Adolesc Psychiatry. 1993;32(6):1283-1291.

115. Roy A, Roy M, Deb S, Unwin G, Roy A. Are opioid antagonists effective in attenuating the core symptoms of autism spectrum conditions in children: a systematic review. J Intellect Disabil Res. 2015; 59(4):293-306.

116. Adler BA, Wink LK, Early M, et al. Drug-refractory aggression, selfinjurious behavior, and severe tantrums in autism spectrum disorders: a chart review study. Autism. 2015;19(1):102-106.

117. Schubart JR, Camacho F, Leslie D. Psychotropic medication trends among chidren and adolescents with autism psectrum disorder in the Medicaid program. Autism. 2014;18(6):631-637.

118. Wink LK, Pedapati EV, Horn PS, McDougle CJ, Erickson CA. Multiple antipsychotic medication use in autism spectrum disorder. J Child Adolesc Psychopharmacol. Epub October 14, 2015.

119. Gallego JA, Nielsen J, De Hert M, Kane JM, Correll CU. Safety and tolerability of antipsychotic polypharmacy. Expert Opin Drug Saf. 2012; 11(4):527-542.

120. Ghaleiha A, Asadabadi M, Mohammadi MR, et al. Memantine as adjunctive treatment to risperidone in children with autistic disorder: a randomized, double-blind, placebo-controlled trial. Int J Neuropsychopharmacol. 2013;16(4):783-789.
121. Ghaleiha A, Mohammadi E, Mohammadi MR, et al. Riluzole as an adjunctive therapy to risperidone for the treatment of irritability in children with autistic disorder: a double-blind, placebo-controlled, randomized trial. Paediatr Drugs. 2013;15(6):505-514.

122. Mohammadi MR, Yadegari N, Hassanzadeh E, et al. Double-blind, placebo-controlled trial of risperidone plus amantadine in children with autism: a 10-week randomized study. Clin Neuropharmacol. 2013;36(6): 179-184.

123. Wink LK, Erickson CA, Stigler KA, McDougle CJ. Riluzole in autistic disorder. J Child Adolesc Psychopharmacol. 2011;21(4):375-379.

124. Erickson CA, Chambers JE. Memantine for disruptive behavior in autistic disorder. J Clin Psychiatry. 2006;67(6):1000.

125. Erickson CA, Veenstra-Vanderweele JM, Melmed RD, et al. STX209 (arbaclofen) for autism spectrum disorders: an 8-week open-label study. J Autism Dev Disord. 2014;44(4):958-964.

126. Bronsard V, Paul C, Prey S, et al. What are the best outcome measures for assessing quality of life in plaque type psoriasis? A systematic review of the literature. J Eur Acad Dermatol Venereol. 2010; 24(Suppl 2):17-22.

127. Stigler KA, McDougle CJ. Pharmacotherapy of irritability in pervasive developmental disorders. Child Adolesc Psychiatr Clin N Am. 2008; 17(4):739-752; vii-viii.

128. Centers for Disease Control and Prevention. Autism Spectrum Disorder, Data and Statistics. Atlanta, GA: Centers for Disease Control and Prevention; 2014. Available from: http:/www.cdc.gov/ncbddd/ autism/data.html. Accessed April 26, 2016.

129. Minshawi N, Wink LK, Shaffer R, et al. A randomized, placebocontrolled trial of D-cycloserine for the enhancement of social skills training in autism spectrum disorders. Mol Autism. 2016;7(2):1.
Neuropsychiatric Disease and Treatment

\section{Publish your work in this journal}

Neuropsychiatric Disease and Treatment is an international, peerreviewed journal of clinical therapeutics and pharmacology focusing on concise rapid reporting of clinical or pre-clinical studies on a range of neuropsychiatric and neurological disorders. This journal is indexed on PubMed Central, the 'PsycINFO' database and CAS,

\section{Dovepress}

and is the official journal of The International Neuropsychiatric Association (INA). The manuscript management system is completely online and includes a very quick and fair peer-review system, which is all easy to use. Visit http://www.dovepress.com/testimonials.php to read real quotes from published authors. 